\title{
Is pornography associated with sexual dysfunction?
}

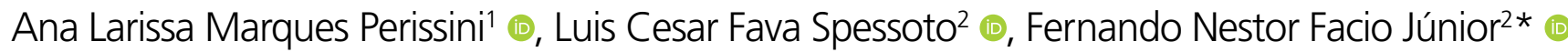

The consumption of digital pornography for the purpose of sexual excitation is a phenomenon that grows every year in countries with unrestricted access to the Internet due to its easy access and anonymity ${ }^{1}$. In a world that has become more digital during the coronavirus disease 2019 (COVID-19) pandemic, contact with different types of virtual sexual contents has enabled individuals in isolation to maintain their sexual practices, popularizing a modality that had already been growing among adults and adolescents in recent years and alerting society about how this new sexual standard is being molded $^{2}$. The ease, diversity, and level of excitation that can be achieved with online pornography indicates that it may operate as a supernatural stimulus, leading the Internet to become the most important means of the dissemination of pornographic content ${ }^{1}$.

The consumption of pornography per se is not a disease but can become one when sexual excitation achieved through the online material becomes dominant over experiences with real sexuality and it takes on the characteristics of dependence ${ }^{3}$. There are several unresolved issues regarding the nature and magnitude of these effects, but pornography may fit the structure of addiction, considering the similar mechanisms as those found with chemical compounds, triggering potential effects on health, especially sexual dysfunctions, with strong evidence of a reduction in sexual satisfaction ${ }^{1}$. Impulsivity in sexual behavior, classified as compulsive sexual behavior disorder in the Diagnostic and Statistical Manual of Mental Disorders, $5^{\text {th }}$ edition (DSM-5) and International Classification of Diseases, $11^{\text {th }}$ Revision (ICD-11), is a characteristic often highlighted in the problematic use of pornography ${ }^{4}$, including among individuals with complaints of sexual dysfunction.

A low desire for sex with one's partner has become a common observation in clinical practice, as men seek help due to excessive sexual behavior and use pornography combined with masturbation. Studies offer evidence of an increase in sexual difficulties among young men in recent years ${ }^{5}$. The most common diagnosis is erectile dysfunction of a psychogenic nature, low prevalence of an organic origin, anorgasmia, and premature ejaculation, generally associated with depressive symptoms, increased anxiety, stress, and a lack of motivation ${ }^{4}$.

Emotional symptoms, behavioral problems, misinformation about sex, difficulties in affective relations, and an unhealthy lifestyle are common among a large part of consumers of online pornography and hinder the evaluation of the true cause of sexual dysfunction ${ }^{5}$. As a phenomenon of contemporary society with little research on the effects of the consumption of digital pornography, further studies are needed to elucidate this issue.

\section{AUTHORS" CONTRIBUTION}

ALMP: Conceptualization, Formal analysis, Supervision, Validation, Writing - original draft, Writing - review \& editing. LCFS: Conceptualization, Formal analysis, Validation, Writing - original draft, Writing - review \& editing. FNFJ: Conceptualization, Formal analysis, Validation, Writing - original draft, Writing - review \& editing

\footnotetext{
${ }^{1}$ Faculdade de Medicina de São José do Rio Preto, Fundação Faculdade Regional de Medicina de São José do Rio Preto, Health Sciences PostGraduation Program - São José do Rio Preto (SP), Brazil.

${ }^{2}$ Faculdade de Medicina de São José do Rio Preto, Fundação Faculdade Regional de Medicina de São José do Rio Preto, Department of Urology São José do Rio Preto (SP), Brazil.

*Corresponding author: fnfacio@yahoo.com.br

Conflicts of interest: the authors declare there are no conflicts of interest. Funding: none.

Received on February 09, 2021. Accepted on March 14, 2021.
} 


\section{REFERENCES}

1. Dwulit AD, Rzymski P. The potential associations of pornography use with sexual dysfunctions: an integrative literature review of observational studies. J Clin Med. 2019;8(7):914. https:// doi.org/10.3390/jcm8070914

2. Perissini ALM, Spessoto LCF, Fácio Júnior FN. Does online pornography influence the sexuality of adolescents during COVID-19? Rev Assoc Med Bras. 2020;66(5):564-5. https:// doi.org/10.1590/1806-9282.66.5.564

3. Pizzol D, Bertoldo A, Foresta C. Adolescents and web porn: a new era of sexuality. Int J Adolesc Med Health.
2016;28(2):169-73. https://doi.org/10.1515/ijamh2015-0003

4. Grubbs JB, Gola M. Is pornography use related to erectile functioning? Result from cross-sectional and latent growth curve analyses. J Sex Med. 2019;16(1):111-25. https://doi. org/10.1016/j.jsxm.2018.11.004

5. Landripet I, Štulhofer A. Is pornography use associated with sexual difficulties and dysfunctions among younger heterossexual men? J Sex Med. 2015;12(5):1136-9. https:// doi.org/10.1111/jsm.12853 